\title{
Emotional Intelligence and Teaching Self-Efficacy as Predictors of Teaching Ability
}

\author{
Dr. Ofra Walter \& Amasha Marcel
}

Received: May 30, 2012

Accepted: July 12, 2013

Published: August 1, 2013

doi:10.5296/jse.v3i3.3785

URL: http://dx.doi.org/10.5296/jse.v3i3.3785

\begin{abstract}
Emotional Intelligence (EI) has proved to be a promising concept in the fields of psychology and education. EI is still being regarded cautiously as a 'gold standard' for measurement and prediction for acceptance for teacher training program. This study examines the potential contribution of four measures - EI, teaching self-efficacy (TSE), psychometric exam grades, and grades of teaching skills during field training. The research population comprised 100 student teachers from college in northern Israel. The findings will help to shed more light on the implications of EI and point to future directions in the evaluation, selection and training of excellent teachers.
\end{abstract}

Keywords: Emotional intelligence, Psychometric exam grades, Teaching self-efficacy, Teaching skills grades 


\section{Introduction}

Student teachers admitted to a teacher training program are required to meet standard admission criteria generally required by academic colleges and universities. These criteria include high school matriculation and psychometric exam grades (Milgrom, 2012), namely, cognitive indices. High school matriculation exam grades are perceived to be a common evaluation basis, however, as a matter of fact, a considerable percentage of the population is not eligible for a high school matriculation certificate. Today, high school matriculation exams are being criticized for obstructing educational renewal and the modification of teaching methods and serving as teachers' evaluations (Harackieweicz, Barron, Tauer \& Elliot, 2002, 562).

In the past two decades, there has been increasing awareness of alternative evaluation methods of achievement (Birenboim, 1997). Teacher training programs are strongly emphasizing success in and mastery of teaching skills, which is manifested through field work. Teaching skills include the mastery and understanding of standard criteria, such as content knowledge, learners' knowledge, pedagogical-didactic knowledge, curricula knowledge, pedagogical content knowledge, thinking skills and reflective skills. In recent years, emotional intelligence and self-efficacy have enhanced their position as important concepts and values in the psychology and education fields.

Research studies have indicated the importance of developing a sense of self-efficacy among students training to become teachers, that is, promoting the concept that the development of emotional abilities among student teachers is as important as cognitive abilities. This orientation will enhance a sense of self-efficacy among teacher trainees in their future educational work (Morris-Rothschild \& Brassard, 2006). Students who demonstrate a high sense of self-efficacy evaluate their academic work as being more efficient and resolve problems more effectively (Bates \& Khasawneh, 2007).

Also, their perseverance is of a higher degree than that demonstrated by students having a lower sense of self-efficacy. Moreover, the concept of emotional intelligence has been proposed as being a complementary measure of human potential (Goleman, 1998). In its relatively short existence in the social science arena, this concept has drawn a large number of supporters, as well as opponents, with differing views being offered in the literature (Cherniss, 2006). Teachers must demonstrate emotional abilities in their field of practice. Therefore, there is a need to deal with the EI abilities of future teachers in particular.

According to Kirk, Schutte and Hine (2008), there is evidence that the adaptation of emotional functioning affects the results related to its action, and this could play a central role in improving teaching skills among both student teachers and veteran teachers. If, as this research proposes, the adaptation of emotional functioning has significant implications on the type of results examined, then there is a convincing claim as to why we should teach the relevant skills for emotional functioning within the teacher training framework in academic colleges and universities, and also use it as an indicator to examine suitability to the teaching profession. 


\subsection{EI in Education}

The concept of Emotional Intelligence (EI) has positioned itself in the fields of psychology and education as a promising concept. Potentially providing added value accounting for a wide range of behaviors that traditional measures such as intelligence or personality could not account for, it is still being regarded cautiously as a 'gold standard' due to the fact that agreement has not yet been reached about the suitable measurement scale for implementing predictions made in this field.

Emotions contain information about an individual's relationships with his environment and could be expressed when the individual-environment relationship changes (Lazarus, 1991). During social interaction, the expression of emotions - both verbal and para-verbal - serves to convey information about an individual's thoughts and those of others, as well as his intentions and behaviors (Buck, 1984; Ekman, 1973; Keltner \& Haidt, 2001). Emotional abilities, including the ability to comprehend, utilize, understand and manage emotions, contribute to the optimization of social functioning (Denham et al., 2003; Eisenberg, Fabes, Guthrie \& Reiser, 2000; Feldman, Philippot \& Custrini, 1991; Nowicki \& Duke, 1994; Savage, 2002). For example, a precise perception of an individual's emotions (based on their classification and intensity) enable predicting and understanding an individual's subsequent actions (Elfenbein, Marsh \& Ambady, 2002). Understanding what is special about emotional situations can be related to diagnosing the attention guiding an individual in his relationship to the environment, to his decision-making process and to his behavioral responses (Damasio, 1999). Effective coping using emotions also represents a critical factor in optimizing social functioning, and this skill enables an individual to express suitable emotions and proper social behavior (Gross, 1998).

Processing intelligence and the effective management of emotional information is essential for navigating in the social world (Keltner \& Kring, 1998). The theory of EI, which clearly expresses the cognitive and emotional mechanisms lying at the basis of emotional information processing provides a uniform framework for studying the place of emotional ability in the social functioning framework (Mayer \& Salovey, 1997). The theory deals with the inherent differences in individuals regarding their ability to identify their own emotions and those of others, and in their ability to overcome emotional problems and carry out a detailed mapping of intelligence penetration into emotions. This enables presenting a theoretical model that focuses on the emotional skills that could be developed through learning and experience.

At the basis of this lies four central abilities: perceiving - the ability to identify and decipher the emotions through facial expressions, pictures, voices and objects, the ability to identify the emotions themselves, and self-awareness about emotions; using - the ability to harness emotions for cognitive processes, for example, thinking and problem solving, and using emotions to accomplish a task successfully; understanding - the ability to understand the language of emotions, the subtleties within different emotions (happiness as opposed to ecstasy), and the potential of developing emotions over time (shock that becomes sadness and pain); and managing - the ability to control and regulate emotions both in ourselves and in 
others according to a certain situation, and the ability to harness emotions with the intention of achieving a certain target (motivation) (Mayer \& Salovey, 1997).

EI is the ability to identify and understand emotions that affect us, and use them in order to cope with ourselves, with others and with environmental pressures and demands. In addition, just like emotionally intelligent individuals accept the approach of healthy and effective information guiding our tendencies to act, they make effective use of emotions for guiding adaptive actions that could help less emotionally intelligent individuals cope with emotions. In this context, the evaluation of EI is very relevant for teachers who provide instruction, teaching and advice to students in educational frameworks.

The teaching profession involves working with a high emotional component and therefore requires emotional capabilities (Hochschild, 1983). Emotional work is work in which a worker must express emotions in order to succeed in his job. Job-holders in this type of work report high levels of job erosion, and teaching is one of the professions found at high risk. Teachers deal constantly with situations in which emotions are involved, and it is vital to develop and foster their emotional abilities (Kremenitzer \& Miller, 2008). Even though emotions are an integral part of a teacher's work (Kuncel et al., 2004), influencing his behavior and motivation and as a result his teaching effectiveness, only a small number of research studies have been carried out in this area (Sutton \& Wheatley, 2003). EI could be developed and fostered among teachers in general and early childhood teachers in particular, using various tools. These tools will increase awareness about EI components among teachers and enable them to be more conscious of what is going on both with themselves and with their students. Increasing self-awareness among teachers will also help to impart awareness about EI to their students (Kremenitzer \& Miller, 2008). The teacher training framework is intended to train, provide support and foster teaching skills, but the success of the training also depends on the student teachers' abilities and emotions. Imparting greater awareness to students about EI components will help them develop these teaching skills (Cherniss, 2000).

The potential contribution of the concept of EI in educational settings is by now widely recognized yet insufficiently tested empirically (Humphrey et al., 2007). Most of the existing literature is not empirical, and the little there is focuses mainly on EI's relevance to effective learning by the students and their adjustment in school and college settings (e.g., Fernandez-Barrocal \& Ruiz, 2008; Mayer, Roberts \& Barsade, 2008). Another part of the literature focuses on teaching EI or emotional management skills in educational settings. Most recently, Jennings and Greenberg (2009) proposed promoting teachers' social emotional competencies through stress reduction and mindfulness programs. Sutton \& Wheatley (2003) experimented with emotional regulation, and Chan (2004) suggested improving teachers' self-efficacy as a means of increasing EI in teachers. Gibbs (2003) claimed that teachers need to develop the capacity to exercise control over their internal world (emotions, thoughts and beliefs) and in this way improve their teaching abilities. Shapiro (2009) believes that through the expression of emotional identity, teachers can develop greater reflexivity, stronger solidarity and heightened sensitivity towards their colleagues and students. However, to date there is no direct empirical examination of the relationship between EI and a teacher's teaching skills. 


\subsection{Self-Efficacy}

Bandura's theory of self-efficacy contains two expectancies: self-efficacy and outcome efficacy. Self-efficacy expectancy provides individuals with a way of deciding whether they have the ability to perform a required task at a desired level of competency, while outcome expectancy provides them with a way of deciding if they have accomplished a task at a desired level (Tschannen-Moran et al., 1998). Researchers have used Bandura's theory in the field of education in order to study teacher self-efficacy. Two dimensions of teacher efficacy have been found consistently to be independent measures - personal teaching efficacy and general teaching efficacy, sometimes referred to as outcome efficacy (Woolfolk-Hoy \& Burke-Spero, 2005). Personal teacher efficacy is generally defined as a teacher's belief in his/her skills and abilities to impact student achievement positively, while general (outcome) teaching efficacy has been defined as a teacher's belief that the educational system can work for all students, regardless of outside influences such as socio-economic status and parental influence (Kuncel et al., 2004).

In considering the context of a student teacher having lower levels of specific content knowledge, we posit that content courses designed to support a teacher's development of content knowledge and pedagogy can be a valuable way of increasing self-efficacy levels (Zajacova et al., 2005, 677). This is consistent with studies that have shown that content courses focusing on how to teach content have been successful in raising student teachers' efficacy levels (Appleton, 1995; Palmer, 2001). Moreover recent results had indicated that teacher's self-efficacy may predict satisfactory teaching abilities and B.Ed scores in general (Walter, Amacha, 2013).

This research examines the contribution of the potential of three measures: EI, TSE, and the grades of teaching skills given within the teacher training framework. The research will examine two values - EI and self-efficacy - and their relationship to student teachers' abilities in teaching skills measured according to the grade evaluating their skills.

The relationship between the two components of EI and TSE and the component of success (the measure of grades) in student teachers' teaching skills within teacher training frameworks will be examined.

The objective of this research is to examine the relationship between EI and social functioning such as in teaching. Proving the existence of a relationship between EI and social functioning will support the literature, which raises the issue and place of emotional abilities in a more qualitative teacher training framework. Many different definitions as well as diverse measuring scales have appeared in research studies carried out to date on the topic of EI. However, controversy still exists regarding the question of the most suitable method for measuring EI (Austin, 2009; Petrides \& Furnham, 2003). Bracket, Rivers, Lerner, Salovey and Shiffman (2006) present two main approaches for studying EI: performance-based tests and a self-report questionnaire.

\section{Methodology}

The sample will include three types of assessment: (1) EI exam; (2) TSE exam; and (3) 
evaluation of teaching skills. The first two components will be measured using a self-report questionnaire. The evaluation of students' teaching skills will be made by documenting the evaluations of the student teachers' instructors during the teaching process, as well as by carrying out a summating teaching exercise whereby the instructors' evaluations are conducted according to uniform observation and evaluation criteria.

Analysis of this research structure will help in examining the research hypothesis suggesting that EI represents a sufficient explanation for the level of teaching skills based on the two criteria mentioned above - EI and TSE, without need for relating to the cognitive or personality factors of the research subjects. This finding will help shed more light on the structure, assumptions and implications of the theoretical concept of EI, as well as point to future directions in the evaluation, selection, and training of excellent teachers.

\subsection{The Current Study and Its Significance}

This study aims at examining the relative void of empirical evidence regarding the role of EI in understanding teaching skills and abilities. We intend to assess EI using two representative measures: a self-report questionnaire and a performance-based test, alongside traditional measures of cognitive abilities and personality measures to account for the variability in teaching skills among student teachers in various stages of their training.

Such evidence will offer new empirical, quantitative evidence that will allow better insights into: (a) the consequences and predictive validity of EI on the conceptual model, while comparing it to assessment approaches (cognitive abilities) used; and (b) providing educational scholars and experts with new practical, evidence-based knowledge regarding future practices in preparing excellent effective teachers.

In light of the above, we hypothesize that:

1. EI will account for the variance in student teachers' teaching skills assessment (by instructors in the field) beyond that accounted for by cognitive and personality factors.

2. EI will account for the variance in student teachers' teaching performance in an assessment teaching task beyond that accounted for by cognitive and personality factors.

3. EI will account for and affect the TSE of student teachers.

\subsection{Research Method}

A research study testing concurrent validity predicated on correlational and comparative designs will provide evidence for testing our hypotheses. A power analysis yielded about $40 \%$ factor tested; therefore, we aim at testing our hypotheses in a sample of 100 student teachers.

\subsection{Research Sample}

Hundred student teachers attending a teaching training college in northern Israel were recruited. The students are proportionally representative sample in terms of gender $(90 \%$ female, 10\% male), age (traditional students) and ethnic background (about 80\% Israeli Jews, the rest Israeli-Arabs of Muslim, Christian and Druze origins). 
Participation was voluntary, and an access was provided to the researchers of the college records of each participant.

\subsection{Research Tools}

1. Self-report EI was assessed using SREIT (Schutte et al., 1998), a 33-item, self-report questionnaire that assesses various aspects of EI based theoretically on the four-tier EI model by Mayer, Salovey and Caruso (2000). The 33-item self-report questionnaire was five-point scaled ( $1=$ strongly disagree to $5=$ strongly agree), and assessed three broad dimensions: (a) the appraisal and expression of emotions, consisting of 13 items; (b) the regulation of emotions, consisting of 10 items; and (c) the utilization of emotions, consisting of 10 items. According to Schutte et al. (1998), SREIT has good predictive and discriminant validity, and high results of reliability, with an alpha Cronbach value $(\alpha)$ of 0.90 . Examples of SREIT items include, "I am aware of the non-verbal messages I send to others" and "I easily recognize my emotions as I experience them."

TSE was measured using a questionnaire developed by Dellinger (2001) that evaluates teachers' faith in their ability to perform specific teaching-related tasks. The questionnaire includes 31 statements and consists of four different factors: adjusting to interpersonal differences; preserving a positive class climate; monitoring and feedback of learning; and routing learning management. The questionnaire's reliability is high, as reported by Dellinger. The alpha Cronbach value of each of the above-mentioned factors exceeds 0.80 . The reliability of each item in the questionnaire ranges from 0.0.92-75. Since the correlations were high, namely, above 0.90 for the four aforementioned factors, it was decided that a data analysis would refer to general teaching self-efficacy as one factor for which a single grade was calculated, constituting the subjects' mean responses for all of the questionnaire's statements.

2. Cognitive abilities are often referred to in the psychological literature as General Mental Ability (GMA). This concept has been represented in research by a wide range of proxies and indicators, ranging from general knowledge to vocabulary tests and academic proficiency tests (the Israeli psychometric exam, the American SAT, etc.). These tests traditionally show very high correlations with traditional and dedicated measures of cognitive abilities, ranging in the 80-90s (Schmidt \& Hunter, 1997; Nevo et al., 2006). Based on the above findings, we intend to use the participants' psychometric exam grades (or their combination grade - a calculated equivalent used in college-level entry procedures in Israel) as a proxy indicator of general cognitive ability.

3. Teaching skills were assessed by documenting the students' evaluations that were conducted by their pedagogical instructors in the field using an evaluation form. The evaluation is based on teaching components that assess the student teacher's lesson teaching performance on a weekly basis.

\subsection{Procedure}

The student teachers were approached in compulsory courses in each of their three years of studies. They were recruited on a voluntary basis, and took the tests and measures as 


\section{Macrothink}

described above. We received access to the student teachers' files (only to the field study records) to extract their evaluations in the field and their cognitive grade (psychometric and high school matriculation exam grades). Data were entered in AMOS, and analyzed accordingly using Path analyses and multiple hierarchical regressions according to the assumed model.

\subsection{Research Model}

The model summarizes the research assumptions: EI components are interrelated and affect the beliefs of student teachers in their self-efficacy; the high school matriculation and psychometric exam grades are related to each other and affect the two important components in the teacher training - success in their theoretical courses, and success in their practical work.

In addition, we assume that self-efficacy also affects success in the student teachers' theoretical courses and practical work, and mediates the relationships between EI components and the grade in practical work and the average grade in the theoretical courses.

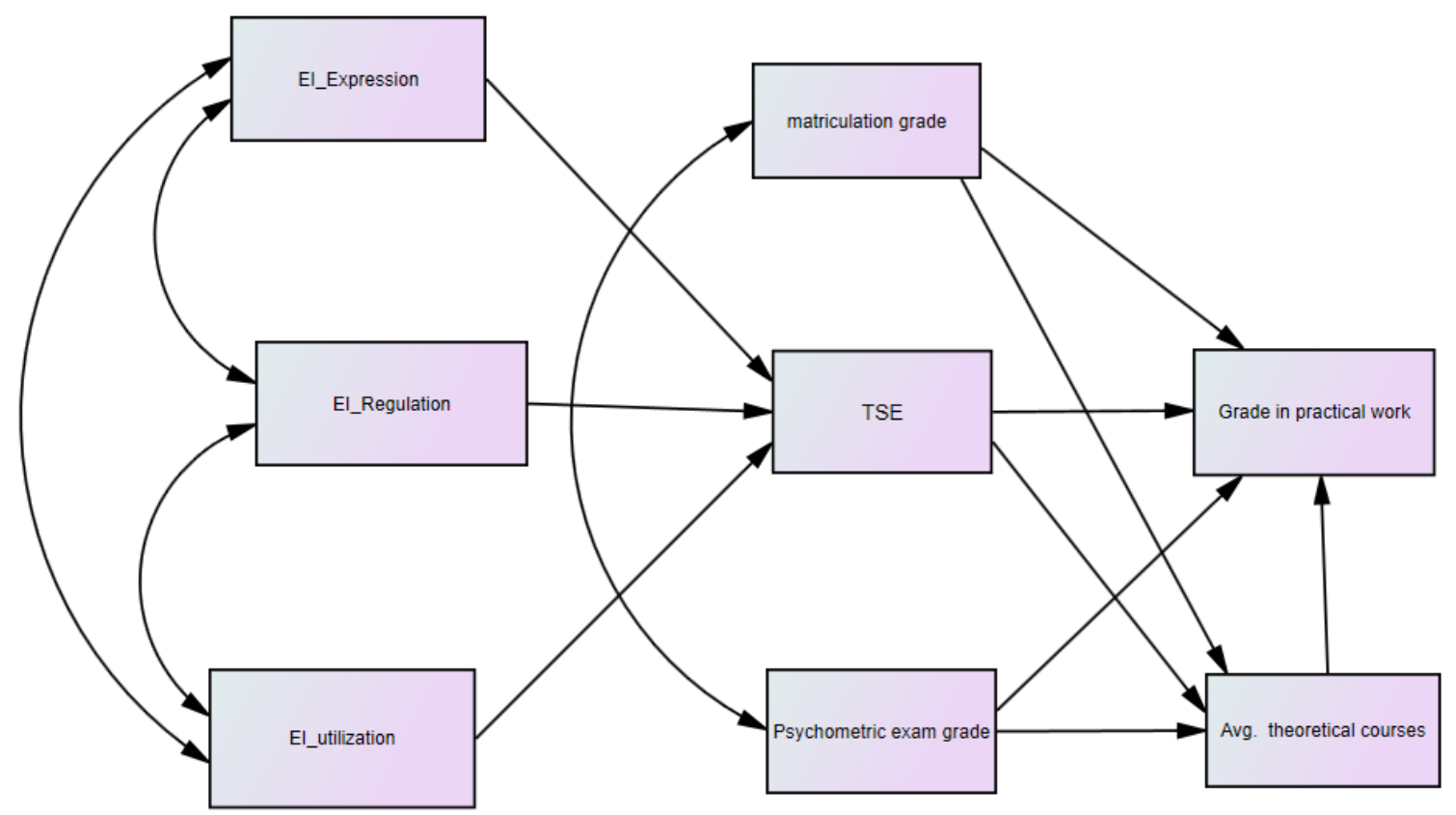

Figure 1. The assumed model.

\section{Findings}

This research study examined to what extent the above model connects between EI and TSI components of student teachers, their achievements in high school matriculation and psychometric exams, their theoretical courses taken during their studies towards a BEd 


\section{Macrothink Institute ${ }^{\text {TM }}$}

degree, and their teaching abilities in practice. . First, descriptive findings will be presented. Then, findings of a multi-variable analysis of the proposed model will be presented, accounting for the variance in teaching skills within the framework of student teachers' field work.

\section{Descriptive Data}

In order to outline the achievements within the student teachers' sample, averages and standard deviations for each variable were calculated, as presented in Table 1:

Table 1. Findings and standard deviations of the research variables

\begin{tabular}{|l|l|l|}
\hline Research Variables & & \\
\hline High school matriculation exam & 91.23 & 5.23 \\
\hline Psychometric exam & 478.83 & 57.69 \\
\hline Average grade in theoretical BEd courses & 85.58 & 6.16 \\
\hline TSE & 3.86 & 0.69 \\
\hline Grade in practical work & 86.90 & 6.37 \\
\hline EI in expressing emotions & 3.93 & 0.48 \\
\hline EI in regulation of emotions & 4.12 & 0.45 \\
\hline EI in utilization of emotions & 4.09 & 0.43 \\
\hline
\end{tabular}

\section{Describing the Relationship of the Variables in this Research Study}

The relationship between variables in this study was computed by means of Pearson correlations. Table 2 presents the computation results: 
Table 2. Matrix of correlations between the research variables.

\begin{tabular}{|c|c|c|c|c|c|c|c|}
\hline & $\begin{array}{l}\text { Avg. high } \\
\text { school } \\
\text { matriculation } \\
\text { grade }\end{array}$ & $\begin{array}{l}\text { Grade in } \\
\text { practical } \\
\text { work }\end{array}$ & $\begin{array}{l}\text { Avg. } \\
\text { grade in } \\
\text { theoretical } \\
\text { courses }\end{array}$ & $\begin{array}{l}\text { Psychometric } \\
\text { exam grade }\end{array}$ & TSE & $\begin{array}{l}\text { EI in } \\
\text { expressing } \\
\text { emotions }\end{array}$ & $\begin{array}{l}\text { EI in } \\
\text { regulation } \\
\text { of } \\
\text { emotions }\end{array}$ \\
\hline $\begin{array}{l}\text { Grade in } \\
\text { practical } \\
\text { work }\end{array}$ & 0.13 & & & & & & \\
\hline $\begin{array}{l}\text { Avg. grade in } \\
\text { theoretical } \\
\text { courses }\end{array}$ & -0.06 & $0.52 * *$ & & & & & \\
\hline $\begin{array}{l}\text { Psychometric } \\
\text { exam }\end{array}$ & 0.07 & 0.03 & $0.29 * *$ & & & & \\
\hline TSE & 0.13 & $0.42 * *$ & $0.19^{*}$ & $-0.24^{* *}$ & & & \\
\hline $\begin{array}{l}\text { EI in } \\
\text { expressing } \\
\text { emotions }\end{array}$ & $-0.19^{*}$ & -0.01 & 0.12 & 0.00 & 0.12 & & \\
\hline $\begin{array}{ll}\text { EI in } \\
\text { regulation of } \\
\text { emotions }\end{array}$ & $-0.27 * *$ & 0.04 & 0.06 & $-0.27^{* *}$ & $0.49 * *$ & $0.61 * *$ & \\
\hline $\begin{array}{ll}\text { EI in } \\
\text { utilization of } \\
\text { emotions }\end{array}$ & $-0.18^{*}$ & 0.06 & 0.11 & $-0.29 * *$ & $0.49 * *$ & $0.57 * *$ & $0.73^{* *}$ \\
\hline
\end{tabular}

It may be observed that no signficant relationship was found between high school matriculation grade and the grade in practical work, and the average grade in theoretical courses. In addition, no signficant relationship was found between psychometric exam grade and the grade in practical work, but a significatn positive relationship was found with the average grade in theoretical courses. However, a positive relationship was found between TSE and EI, the grade in practical work, and the average grade in theoretical courses. It is interesting to note that a negative significant relationship was found between EI and psychometric and high school matriculation exam grades. Later on we will examine if TSE mediates between the above relationships by changing the model. 


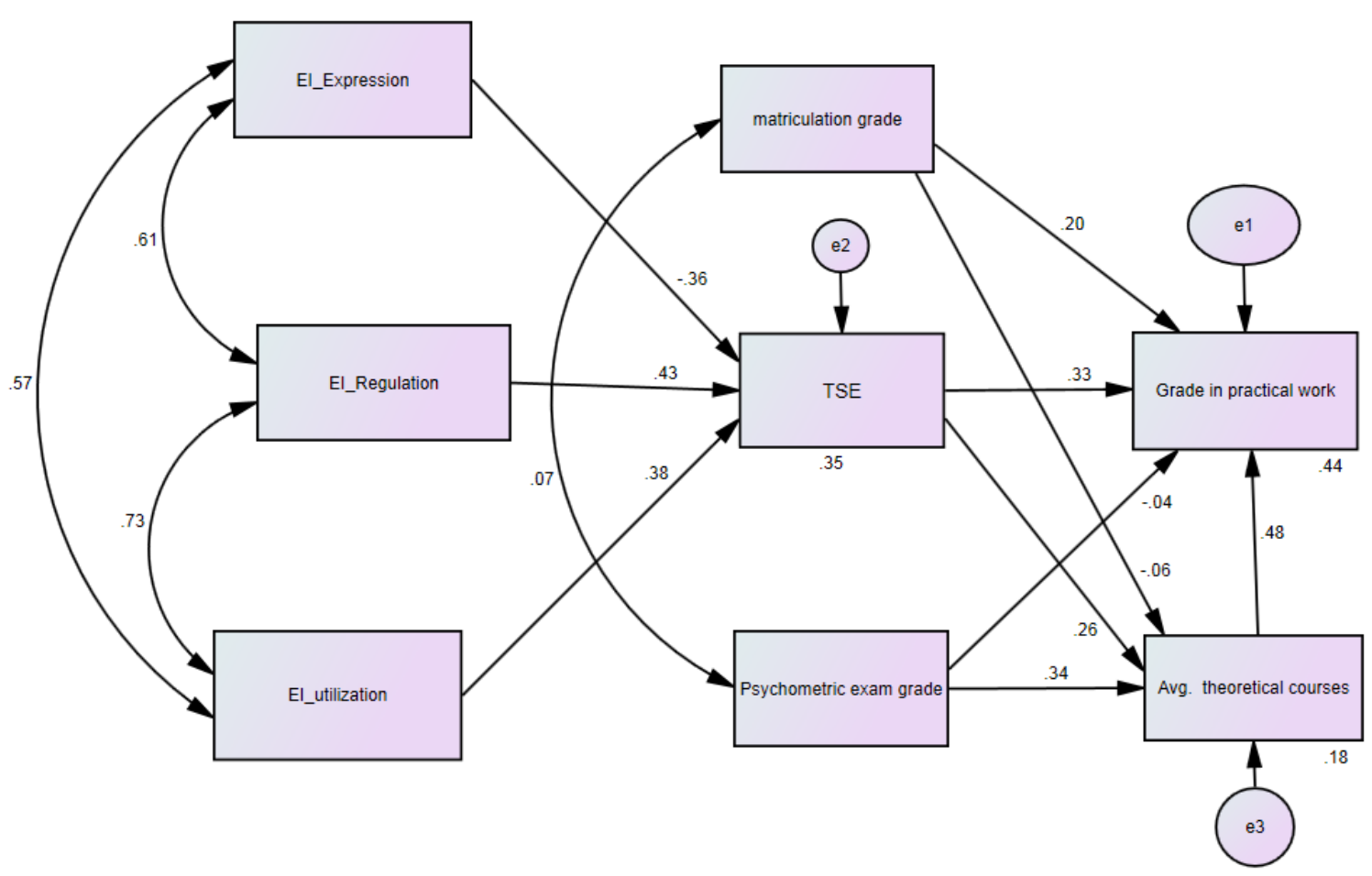

Figure 2. The original model of teaching abilities for the entire research population $(n=100)$.

The goodness of fit of the original model:

$$
\begin{array}{ll}
\checkmark & \chi^{2}=30.98, \chi 2 / \mathrm{df}=2.21 \\
\checkmark & \mathrm{NFI}=0.89 \\
\checkmark & \mathrm{RMSEA}=0.11 \\
\checkmark & \mathrm{R}^{2}=44 \%
\end{array}
$$

The proposed model explains the significant level of variance in the teaching abilities of the student teachers. However, the model does not fit the data well. The proposed model fits the data of the research sample of student teachers and explains the significant level of variance in their TSE. It was found that the proposed model explains $44 \%$ of the variance in grades in practical work of the student teachers, but a high correlation of the model to the data did not exist for the research sample of student teachers. After making conceptual changes in the model, a very good fit was found to the data. However, the model does not fit the data well, therefore we made changes in the model (eliminating the relationship between the average of high school matriculation exam grade and overall BEd grade, and between the psychometric exam grade and the grade in practical work), as illustrated in Figure 3. 


\section{Macrothink}

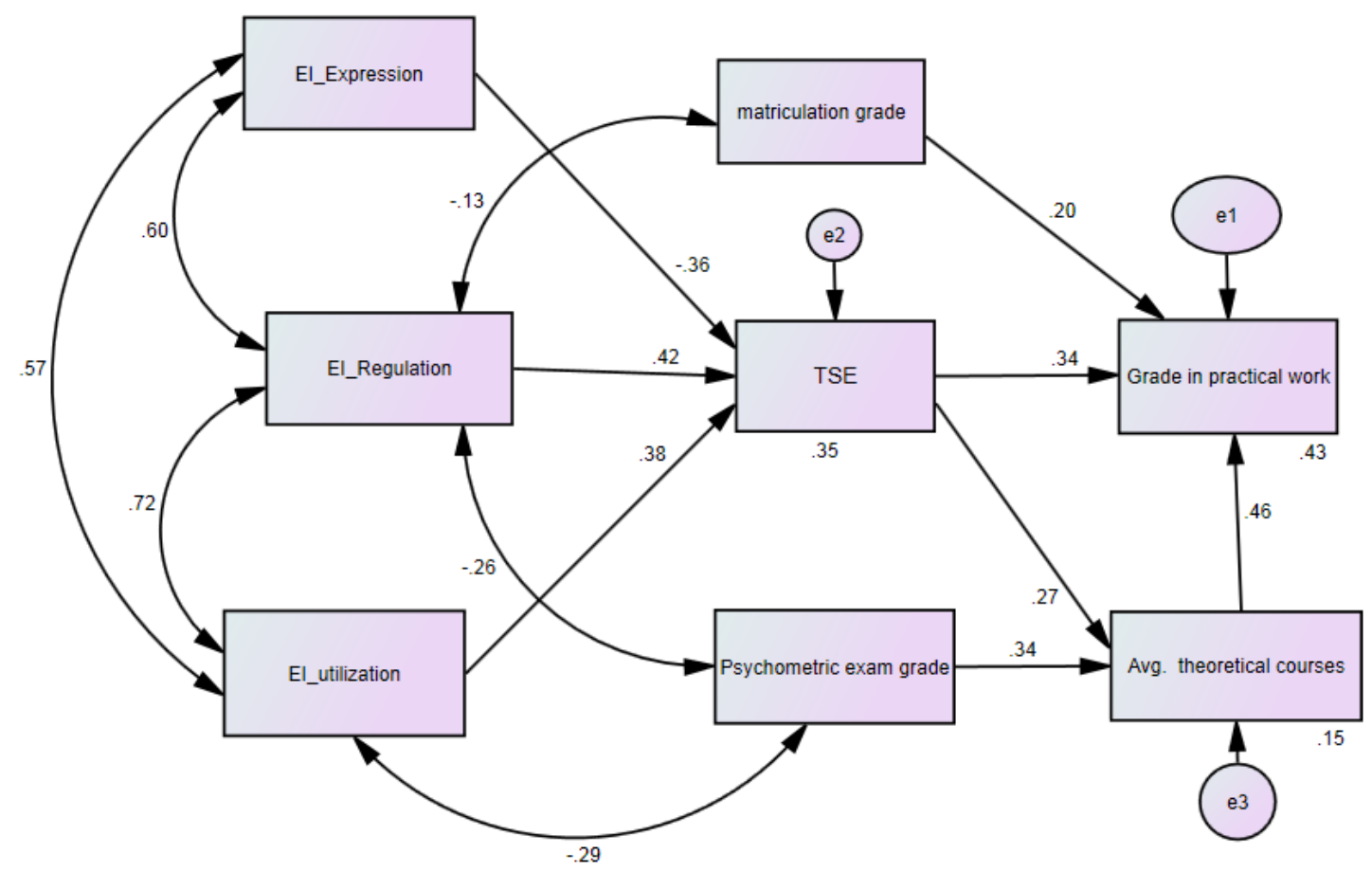

Figure 3. The final model of teaching abilities for the entire research population $(n=100)$.

The goodness of fit of the final model:

$$
\begin{array}{ll}
\checkmark & \chi^{2}=11.68, \chi 2 / \mathrm{df}=0.83 \\
\checkmark & \mathrm{NFI}=0.96 \\
\checkmark & \mathrm{RMSEA}=0.00 \\
\checkmark & \mathrm{R}^{2}=43 \%
\end{array}
$$

The final model was found to be a good fit to the data and explains $43 \%$ of the variance in grades of the practical work. In Table 3 it may be seen that the variance explained in practical work emphasizes the importance of the teachers' belief in their self-efficacy in having a positive influence on the student teachers' success in practical work on the one hand, and the importance of their belief in teaching abilities in mediating the influence of EI over these values on the other hand (direct effect 0.34 and indirect effect 0.13 ). From the final model we see the importance of the indirect positive influence of EI in the regulation of emotions $(0.18)$ and the utilization of emotions $(0.18)$ on the success of the student teacher in practical work. The average high school matriculation grade had a direct positive influence on success in their practical work $(0.20)$ as did the psychometric exam, albeit indirectly, on their success in practical work (0.16). The EI components had a significant indirect effect on the success of the student teachers in their practical work, a positive effect in the regulation and utilization of emotions, and a negative effect in expression emotions. 
Table 3. Effects of the research variables on teaching skills.

\begin{tabular}{|l|r|r|r|}
\hline Research Variables & Direct Effect & \multicolumn{1}{|l|}{ Indirect Effect } & \multicolumn{2}{l|}{ Overall Effect } \\
\hline EI in expressing emotions & & $-.169^{* *}$ & $-.169^{* *}$ \\
\hline EI in regulation of emotions & & $.198^{* *}$ & $.198^{* *}$ \\
\hline EI in utilization of emotions & & $.180^{* *}$ & $.180^{* *}$ \\
\hline Psychometric exam grade & $.201^{* *}$ & $.159^{* *}$ & $.159^{* *}$ \\
\hline $\begin{array}{l}\text { Avg. of high school matriculation } \\
\text { exam grades }\end{array}$ & & & $.201^{* *}$ \\
\hline TSE & $.343^{* *}$ & $.127^{*}$ & $.470^{* *}$ \\
\hline Avg. grades in BEd courses & $.465^{* *}$ & & $.465^{* *}$ \\
\hline
\end{tabular}

\section{Discussion}

This research study examined the suitability of a model that claimed that measures of EI can predict the success of student teachers in teaching. It was found that EI components have a direct significant effect on the success of student teachers in their practical work. The components of regulation and utilization of emotions in EI had a positive effect, however, the component of expressing emotions had a negative effect. The regulation of emotions enables the future teacher to understand the language of emotion and the subtleties between various emotions and their regulation. The ability to utilize emotions imparts to the future teacher control and the ability to manage emotions according to different teaching situations, and the ability to harness emotions with the intention of achieving a certain teaching target (Mayer \& Salovey, 1997, 1990). These abilities are important for teachers who need to develop abilities to control their inner world on the one hand (emotions, thoughts and beliefs) and to be capable of instructing, teaching and advising their students within educational frameworks on the other hand. These abilities help improve their teaching abilities and also add a value of content knowledge and correct teaching methods (Gibbs, 2003). In addition, a teacher who utilizes his emotions will cause his students to be more involved in learning experiences while expressing creativity in their activities (Ergur, 2009). Teaching requires recruiting emotional capabilities (Hochschild, 1983): the conscious ability to separate the teachers' personal emotions and the intelligent emotional response, the ability to avoid expressing emotions of freedom and liberty, and being able to utilize and regulate emotions in his educational position.

Most of the findings indicated that that teaching self-efficacy strongly predicts satisfactory teaching abilities and successful academic performance, and serves as a mediator between EI, teaching abilities and academic performance. These findings support other findings implying that self-efficacy may serve as a mediator between skills, other self-beliefs and performance (Bates \& Khasawneh, 2007, 175) regarding relationships between self-efficacy, 
self-regulation and academic procrastination. It also supported studies that perceived teaching self-efficacy as a strong predictor of academic performance as measured by high school matriculation grades (Zajacova et al., 2005, 677). Student teachers are accepted to the BEd program based on the same grades as any other higher education programs, i.e., high school matriculation and psychometric exam grades. Moreover, student teachers need to demonstrate other skills such as emotional regulation and utilization, and personal abilities including self-regulation and reflection abilities. These abilities are essential for satisfactory teaching abilities.

Most studies examined variables predicting academic performance as expressed by high school matriculation and psychometric exam grades. Yet, recent findings have indicated that high school matriculation grades is a sensitive measure clearly affected by personality traits similar to the personal abilities that are one of the components of effective teaching abilities within the teacher training framework. These findings contradict the results of this research model, which indicates that self-efficacy is a strong predictor of BEd grades and is used as a mediator between EI and teaching abilities. High school matriculation grades are the mean of the final exam grades and the teacher's evaluation, as are motivational variables (Harackieweicz, Barron, Tauer and Elliot, 2002, 562) and other self-related factors (Kuncel et al., 2004).

Interestingly, the high school matriculation and psychometric exam grades have a lesser effect on academic and teaching grades than that of EI and TSE on student achievement. This may sound surprising since the psychometric exam grade is a main prerequisite for acceptance to higher education frameworks; in other words, it is perceived as a predictor of success in academic performance, including the BEd (student teacher) program (Milgrom, 2012).

The psychometric exam grade seems to be less of a predictor for student teachers since student teachers are required to demonstrate strengths in other areas that are most effectively predicted by EI, TSE and some by the high school matriculation grade.

\section{Conclusions}

The current study assessed the relationship between EI and two representative measures: TSE and performance-based exams and teaching assessment grades, alongside traditional measures of cognitive abilities that are a prerequisite of acceptance to higher education frameworks and moreover to teacher training programs.

The hypotheses of the model significantly demonstrated that TSE strongly predicts satisfactory teaching abilities, as well as successful academic performance, and serves as a mediator between EI, teaching abilities and academic performance. In higher education frameworks, it is common in all programs to predict success by cognitive abilities, including the BEd program, although success in this program includes the evaluation of practical teaching abilities that coincide with EI predictors, such as the need for managing and understanding emotions in class situations. Teaching situations require a higher level of emotional abilities in order to be able to solve problems in class and between the teaching 
staff, as well as to be able to provide advice while leaving personal feelings aside. Therefore, student teachers studying in teaching training programs for a BEd degree should reconsider the main acceptance prerequisites for future teachers who will need to use EI skills. The first step would be to include the EI questionnaire grade as part of the prerequisite for acceptance to teacher training programs, and to conduct this research in additional teacher training program frameworks.

\section{References}

Appleton, K. (1995). Student teachers' confidence to teach science: is more science knowledge necessary to improve self-confidence? International Journal of Science Education, 17, 357-369. http://dx.doi.org/10.1080/0950069950170307

Austin, E. J. (2009). A reaction time study of responses to trait and ability emotional intelligence test items. Personality and Individual Differences, 46, 381-383. http://dx.doi.org/10.1016/j.paid.2008.10.025

Bandura, A. (1977). Self-efficacy: toward a unifying theory of behavioral change. Psychological Review, 84, 191-215. http://dx.doi.org/10.1037/0033-295X.84.2.191

Bates, R., \& Khasawneh, S. (2007). Self-efficacy and college students' perceptions and use of online learning systems. Computers in Human Behavior, 23, 175-191. http://dx.doi.org/10.1016/j.chb.2004.04.004

Harackiewicz, J. M., Barron, K. E., Pintrich, P. R., Elliot, A. J., \& Thrash, T. M. (2002). Revision of achievement goal theory: necessary and illuminating. Journal of Educational Psychology, 94, 638-645. http://dx.doi.org/10.1037/0022-0663.94.3.638

Birenboim, M. (1997). Alternatives in assessing achievements, Tel Aviv: Ramot Press.

Brackett, M. A., \& Mayer, J. D. (2003). Convergent, discriminant, and incremental validity of competing measures of emotional intelligence. Personality and Social Psychology Bulletin, 29, 1147-1158. http://dx.doi.org/10.1177/0146167203254596

Buck, R. (1984). The communication of emotion. New York: Guilford Press.

Chan, D. W. (2004). Perceived emotional intelligence and self-efficacy among Chinese secondary school teachers in Hong Kong. Personality and Individual Differences, 36, 1781-1795. http://dx.doi.org/10.1016/j.paid.2003.07.007

Cherniss, C. (2006). Emotional intelligence: what does the research really indicate? Educational Psychologist, 41(4):239-245. http://dx.doi.org/10.1207/s15326985ep4104_4

Damasio, A. (1999). The feeling of what happens: body, emotion and the making of consciousness. London: Vintage.

Dornheim, L. (1998). Development and validation of a measure of emotional intelligence. $\begin{array}{llll}\text { Personality and Individual Differences, } & \text { 25, }\end{array}$ http://dx.doi.org/10.1016/S0191-8869(98)00001-4 
Denham, S. A., Blair, K. A., DeMulder, E., Levitas, J., Sawyer, K., Auerbach-Major, S., \& Queenan, P. (2003). Preschool emotional competence: pathway to social competence. Child Development, 74, 238-256. http://dx.doi.org/10.1111/1467-8624.00533

Eisenberg, N., Fabes, R. A., Guthrie, I. K., \& Reiser, M. (2000). Dispositional emotionality and regulation: their role in predicting quality of social functioning. Journal of Personality and Social Psychology, 78, 136-157. http://dx.doi.org/10.1037/0022-3514.78.1.136

Ekman, P. (1973). Darwin and facial expression: a century of research in review. New York: Academic Press.

Elfenbein, H. A., Marsh, A. A., \& Ambady, N. (2002). Emotional intelligence and the recognition of emotion from facial expressions. In L. F. Barrett, \& P. Salovey (Eds.), The wisdom in feeling: psychological processes in emotional intelligence (pp. 37-59). New York: Guilford Press.

Feldman, R. S., Philippot, P., \& Custrini, R. J. (1991). Social competence and nonverbal behavior. In R. S. Feldman \& B. Rime (Eds.), Fundamentals of nonverbal behavior (pp. 329-350). New York: Cambridge University Press.

Fernandez-Barrocal, P., \& Ruiz, A. (2008). La Inteligencia emocional en la Educación.). Electronic Journal of Research in Educational Psychology, 6(2), 421-436,

Gibbs, C. (2003) Explaining effective teaching: self-efficacy and thought control of action. Journal of Educational Enquiry, 4(2), 1-14.

Goleman, D. (1998). Working with emotional intelligence. New York: Bantam Books.

Gross, J. J. (1998). The emerging field of emotion regulation: an integrative review. Review of General Psychology, 2, 271-299. http://dx.doi.org/10.1037/1089-2680.2.3.271

Hemenover, S. (2002). What do we assess when we assess a big 5 trait? A content analysis of the affective, behavioral, and cognitive processes represented in big 5 personality inventories. $\begin{array}{lllll}\text { Personality } \quad \& \quad \text { Social Psychology } & \text { Bulletin, } & 28(6), & 847 .\end{array}$ http://dx.doi.org/10.1177/0146167202289013

Hochschild, A. (1983). The managed heart: commercialization of human feeling. Berkeley: University of California Press.

Humphrey, N., et al. (2007). Emotional intelligence and education: a critical review. Educational Psychology, 27(2), 235-254. http://dx.doi.org/10.1080/01443410601066735

Jennings, P. A., \& Greenberg, M. T. (2009). The prosocial classroom: teacher social and emotional competence in relation to student and classroom outcomes. Review of Educational Research, 79, 1491-1525. http://dx.doi.org/10.3102/0034654308325693

Kentle, R. (1994). Correlation of grades on the Eysenck personality inventory with those on the Gordon personal. Psychological Reports, 75(2), 905.

Keltner, D., \& Kring, A. M. (1998). Emotion, social function, and psychopathology. Review 
of General Psychology, 2, 320-342. http://dx.doi.org/10.1037/1089-2680.2.3.320

Keltner, D., \& Haidt, J. (2001). Social functions of emotions. In T. J. Mayne \& G. A. Bonanno (Eds.), Emotions: current issues and future directions: emotions and social behavior (pp. 192-213). New York: Guilford Press.

Kirk, B. A., Schutte, N. S., \& Hine, D. W. (2008). Development and preliminary validation of an emotional self-efficacy scale. Personality and Individual Differences, 45, 432-436. http://dx.doi.org/10.1016/j.paid.2008.06.010

Kremenitzer, J. P., \& Miller R. (2008). Are you a highly qualified, emotionally intelligent early childhood educator? Young Children, 63(4), 106-112.

Kuncel, N. R., Hezlett, S. A., \& Ones, D. S. (2004). Academic performance, career potential, creativity, and job performance: Can one construct predict them all? Journal of Personality and Social Psychology, 86, 148-161. http://dx.doi.org/10.1037/0022-3514.86.1.148

Lazarus, R. S. (1991). Progress on a cognitive-motivational-relational theory of emotion. American Psychologist, 46(8), 819-834. http://dx.doi.org/10.1037/0003-066X.46.8.819

Mayer, J., Roberts R., \& Barsade, S. G. (2008). Human abilities: emotional intelligence. Annual Review of Psychology, 59, 507-536.

Mayer, J. D., Salovey, P., \& Caruso, D. R. (2000). Emotional intelligence as zeitgeist, as personality, and as a mental ability. In R. Bar-On, \& J. D. A. Parker (Eds.), The handbook of emotional intelligence (pp. 320-342). San Francisco: Jossey-Bass. http://dx.doi.org/10.1146/annurev.psych.59.103006.093646

McConochie, W. A. (2007). The Big Five Inventory (BFI) manual. Eugene, OR: TestMaster, Inc.

Milgrom, T. What exactly does the psychometric exam predict? MASA Portal, 2012 http://portal.macam.ac.il/ArticlePage.aspx?id=5053 (in Hebrew).

Morris-Rothschild, B. K., \& Brassard, M. R. (2006). Teachers' conflict management styles: the role of attachment styles and classroom management efficacy. Journal of School Psychology, 44, 105-121. http://dx.doi.org/10.1016/j.jsp.2006.01.004

Nevo, I, et al. (2006). Is it wise to teach our students to follow the argument wherever it leads? Teaching Philosophy, 29(2), 157-172.

Nowicki, S., Jr., \& Duke, M. P. (1994). Individual difference in nonverbal communication of affect: the diagnostic analysis of nonverbal accuracy scale. Journal of Nonverbal Behavior, 18, 9-35. http://dx.doi.org/10.1007/BF02169077

Palmer, D. H. (2006). Durability of changes in self-efficacy of preservice primary teachers. International Journal of Science Education, 28(6), 655-671. http://dx.doi.org/10.1080/09500690500404599

Petrides, K. V., \& Furnham, A. (2003). Trait emotional intelligence: behavioural validation in 
two studies of emotion recognition and reactivity to mood induction. European Journal of Personality, 17, 39-57. http://dx.doi.org/10.1002/per.466

Putnam, R. T., \& Borko, H. (2000). What do new views of knowledge and thinking have to say about research on teacher learning? Educational Researcher, 29(1), 4-15. http://dx.doi.org/10.3102/0013189X029001004

Salovey, P. \& Mayer, J. D. (1997). What is emotional intelligence? In P. Salovey \& D. J. Sluyter (Eds.), Emotional development and emotional intelligence: educational implications (pp. 168-195). New York: Basic Books, Inc.

Savage, C. R. (2002). The role of emotion in strategic behavior. In L. F. Barrett, \& P. Salovey (Eds.), The wisdom in feeling (pp. 211-236). New York: Guilford Press.

Schmidt, F., \& Hunter, J. (1997). Development of general solution to the problem validity generalization. Journal of Applied Psychology, 62, 529-540. http://dx.doi.org/10.1037/0021-9010.62.5.529

Schutte, N. S., Malouff, J. M., Hall, L. E., Haggerty, D. J., Cooper, J. T., Golden, C. J., \& Sutton, R. E. (2004). Emotion regulation goals and strategies. Social Psychology of Education, 7, 379-398. http://dx.doi.org/10.1007/s11218-004-4229-y

Shapiro, J., Nguyen, V. P., Mourra, S., Boker, J. R., Ross, M., Thai, T. M., \& Leonard, R.J. (2009). Relationship of creative projects in anatomy to medical student professionalism, test performance and stress: an exploratory study. Med Educ. 3(9), 65.

Sutton, R., \& Wheatley, K. (2003). Teachers' emotions and teaching: A review of the literature and directions for future research. Educational Psychology Review, 15, 327-358. http://dx.doi.org/10.1023/A:1026131715856

Tschannen-Moran, M., Woolfok-Hoy, A., \& Hoy, W. K. (1998). Teacher efficacy: its meaning and measure. Review of Educational Research, 68(2), 202-248. http://dx.doi.org/10.3102/00346543068002202

Walter, O.\& Amacha, M. (2013) . Teaching, Matriculation, and Psychometric Exams Self Efficacy as Teaching Skills Predictors. Journal of Studies in Education, 3(2). http://dx.doi.org/10.5296/jse.v3i2.3388

Woolfolf-Hoy, A., \& Burke-Spero, R. (2005). Changes in teacher efficacy during the early years of teaching: a comparison of four measures. Teaching and Teacher Education, 21(4), 343-356. http://dx.doi.org/10.1016/j.tate.2005.01.007

Zajacova, A., Lynch, S. M., \& Thomas, M. (2005). Self-efficacy, stress and success in college. Research in Higher Education, 46, 677-706. http://dx.doi.org/10.1007/s11162-004-4139-z 